\title{
A word of caution on calculating market- based minimum capital risk requirements
}

Article

Accepted Version

Brooks, C., Clare, A. D. and Persand, G. (2000) A word of caution on calculating market-based minimum capital risk requirements. Journal of Banking \& Finance, 24 (10). pp. 1557-1574. ISSN 0378-4266 doi: https://doi.org/10.1016/S0378-4266(99)00092-8 Available at https://centaur.reading.ac.uk/35965/

It is advisable to refer to the publisher's version if you intend to cite from the work. See Guidance on citing.

Published version at: http://dx.doi.org/10.1016/S0378-4266(99)00092-8

To link to this article DOI: http://dx.doi.org/10.1016/S0378-4266(99)00092-8

Publisher: Elsevier

All outputs in CentAUR are protected by Intellectual Property Rights law, including copyright law. Copyright and IPR is retained by the creators or other copyright holders. Terms and conditions for use of this material are defined in the End User Agreement.

\section{www.reading.ac.uk/centaur}

\section{CentAUR}

Central Archive at the University of Reading 
Reading's research outputs online 
NOTICE: this is the author's version of a work that was accepted for publication in the Journal of Banking and Finance. Changes resulting from the publishing process, such as peer review, editing, corrections, structural formatting, and other quality control mechanisms may not be reflected in this document. Changes may have been made to this work since it was submitted for publication. A definitive version was subsequently published in the Journal of Banking and Finance, 14.10 (2000), DOI: 10.1016/S0378-4266(99)00092-8 


\title{
A Word of Caution on Calculating Market-based Minimum Capital Risk Requirements
}

\author{
by \\ C. Brooks, ISMA Centre, University of Reading, UK, \\ A. D. Clare, Bank of England and ISMA Centre, \\ and \\ G. Persand, ISMA Centre, University of Reading, $U K^{1}$
}

\begin{abstract}
This paper demonstrates that the use of GARCH-type models for the calculation of minimum capital risk requirements (MCRRs) may lead to the production of inaccurate and therefore inefficient capital requirements. We show that this inaccuracy stems from the fact that GARCH models typically overstate the degree of persistence in return volatility. A simple modification to the model is found to improve the accuracy of MCRR estimates in both back- and out-of-sample tests. Given that internal risk management models are currently in widespread usage in some parts of the world (most notably the USA), and will soon be permitted for EC banks and investment firms, we believe that our paper should serve as a valuable caution to risk management practitioners who are using, or intend to use this popular class of models.
\end{abstract}

\section{July 1999}

Keywords: Minimum Capital Risk Requirements, Internal Risk Management Models, volatility persistence

\section{JEL Classifications: C14, C15, G13}

\footnotetext{
${ }^{1}$ The authors are grateful to participants of the 1998 RES, Forecasting Financial Markets and EFA Conferences, and to two anonymous referees, the Editor and an Associate Editor of this journal, and Simon Burke, David Hsieh and Michael Taylor for helpful comments on an earlier version of this paper. The usual disclaimer applies. Address for correspondence: ISMA Centre, Dept of Economics, University of Reading, Whiteknights Park, PO Box 242, Reading, RG6 6BA, UK.
} 


\section{Introduction}

The regulation of the quantity and quality of bank capital has become the most important feature of financial market regulation since the original Basle Accord of 1988. The basic aim of regulators is to require that banks and securities houses maintain sufficient capital to absorb unforeseen losses. Broad agreement exists about the need to impose minimum capital risk requirements (MCRR) in order to maintain the stability of the financial system, however there exists far less agreement about how this minimum amount of capital should be calculated ${ }^{2}$. This disagreement is most apparent in the wide range of ways in which MCRRs can be calculated for positions in traded securities. At the time of writing, MCRRs may be set by using the Standard/Internal Model Approach of the Basle Accord, the Building-Block Approach of the EC Capital Adequacy Directive (known as CAD), the Comprehensive Approach of the U.S.'s SEC, the Pre-commitment Approach of the Federal Reserve Board, or by using the Portfolio Approach of the Securities and Futures Authority of the United Kingdom ${ }^{3}$.

We address an approach to the calculation of MCRRs which is similar in spirit to the approach adopted in many Internal Risk Management Models (IRMM), and which involves the calculation of the institution's value at risk (VaR) inherent in its trading book positions. $\mathrm{VaR}$ is an estimation of the probability of likely losses which might occur from changes in market prices from a particular securities position, and the MCRR is defined as the minimum amount of capital required to absorb all but a pre-specified percentage of these possible losses. The Basle Accord of the BIS has agreed that banks should be allowed to use their own IRMMs models as long as these models are "sound", i.e., that they have been properly back

\footnotetext{
${ }^{2}$ See, for example, Cantor and Packer (1997) on the impact of credit ratings on capital requirements.

${ }^{3}$ Dimson and Marsh (1995) provide a thorough comparison of the Building-Block, Comprehensive and Portfolio Approaches.
} 
and stress tested. The Accord requires that the MCRRs calculated using IRMM should be

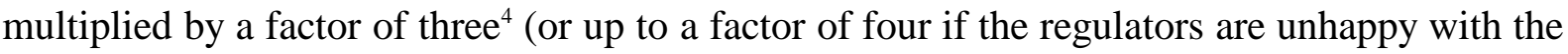
IRMM). These models will become more important for European banks and investment firms who are currently obliged to comply with the CAD. Under a revised version of CAD (known as CAD II which will supersede the original version once the necessary legislation has been passed $^{5}$ ), their use will be permitted. The experience of financial institutions who already use IRMMs under the Basle regulations shows that the use of such models can reduce the necessary capital charges for market risks compared with the current EC building block approach. Given the importance of setting appropriate MCRRs (and the potential costs involved in setting inappropriate standards) it is equally important that academics and practitioners alike continue to investigate this methodology. It is expected that financial institutions in London will be in a position to implement IRMMs soon after the necessary legislation has been passed (for a fuller discussion of the implications of CAD II see Clifford Chance (1998)).

In this paper we extend the work of Hsieh (1993), and calculate MCRR's for three of the most popular financial futures contracts traded on the London International Financial Futures Exchange (LIFFE) - the FTSE-100 stock index futures contract, the Short Sterling contract and the Gilt contract. We also place considerable emphasis on out-of-sample tests of our models, a practice which is not commonly undertaken in this literature. Recent derivatives disasters, for example, see the cases of Barings, Metallgesellschaft, Orange County or Daiwa, have highlighted the need for a better understanding of the risks inherent in derivatives

\footnotetext{
${ }^{4}$ This bizarre rule is a compromise. US regulators wanted institutions to be able to use the "raw" MCRR value generated by the model, while the German delegation wanted this number to be multiplied by a factor of 5 . The multiple of 3 represented a compromise - half way between the multiples of 1 and 5 !

5 The proposal is due to be adopted by the EU's Council of Ministers, and the European Parliament under the codecision procedure.
} 
positions. The motivation of this paper is to calculate appropriate minimum capital risk requirements for these three derivatives and to highlight a potentially serious problem with the basic methodology of using estimated conditional variance models for forecasting volatility as an input to risk management models.

The most important finding in this paper is that the MCRRs which we calculate here based upon ARCH-type models of conditional volatility, are considerably larger when they are calculated with disregard for the commonly found "excessive volatility persistence" implied in ARCH-type models compared with an approach which we propose here which takes account of this phenomenon. The observed excess persistence leading to excessive capital risk requirements confirms the results of Hsieh (1993) in the context of US futures contracts. The difference between the two sets of MCRRs is enough to make a significant impact upon the costs of holding positions in these securities. We also extend previous research in this area to perform out-of-sample tests of the calculated MCRRs which show that the lower MCRR produced by the model which takes account of the excess volatility persistence is adequate for all three futures contracts. The rest of this paper is organised as follows: in Section 2 we present some preliminary exploratory analysis of our data set; in Section 3 we consider alternative models of conditional volatility; we outline our basic methodology for calculating MCRRs in Section 4; in Section 5 we present our results; and we conclude the paper in Section 6 with suggestions for future research.

\section{Data and preliminary analysis}

In this study we calculate MCRRs for three LIFFE futures contracts - the FTSE-100 Index Futures Contract, the Long Gilt Futures Contract and the Short Sterling Interest Rate Futures 
Contract - based upon their daily settlement prices $^{6}$. The data was collected from Datastream International, and spans the period 2 January 1985 to 16th September 1996. The sample period includes the October 1987 stock market crash, and sterling's exit from the European Exchange Rate Mechanism in the September of 1992. Observations corresponding to UK public holidays (i.e., when LIFFE was closed) were deleted from the data set to avoid the incorporation of spurious zero returns, leaving 2961 observations, or trading days in the sample. In the empirical work below, we use the daily log return of the original price series.

It is evident from Table 1 that all three security returns series show strong evidence of leptokurtosis. They are also highly skewed - the FTSE-100 contract returns are skewed to the right while the returns on the Long Gilt and Short Sterling contracts are skewed to the left. The Bera-Jarque test statistic consequently rejects normality for all three derivative return series. The observed non-normality of the asset return distributions provides a strong motivation for the use of a semi-nonparametric procedure, such as that employed here, in the calculation of capital risk requirements.

Following Hsieh (1993), an important issue in the context of MCRR calculations is the extent to which the returns on a security position exhibit non-linear dependence, because this will affect our forecast of the underlying returns series. To this end we make extensive use of the BDS test (Brock, Dechert and Scheinkman, and LeBaron, 1996). The BDS test is asymptotically distributed as a standard normal variate under the null hypothesis of independent and identical distribution (iid). The BDS test can detect many types of non-iid behaviour, including linear dependence, non-stationarity, chaos and non-linear stochastic

\footnotetext{
${ }^{6}$ Because these contracts expire 4 times per year - March, June, September and December - to obtain a continuous time series we use the closest to maturity contract unless the next closest has greater volume, in which case we switch to this contract.
} 
processes (Hsieh, 1991). The test can also be applied to the residuals of a linear or ARCHtype model (a pre-whitening or bleaching process) to see if there is further dependence beyond that described by these models. However, in the case of ARCH-type models (which we employ here in the calculation of the MCRRs for the three derivatives), new critical values for the test statistic have to be estimated because (following ARCH-filtering) the test statistic will no longer be distributed as a standard normal under the null (Brock et al, 1991). Brock et al (1991) give a rigorous theoretical derivation of the test and a number of examples of its use. Based upon Monte Carlo studies of data generated from various distributions, Brock et al suggest that the finite sample distribution can approximate the asymptotic distribution of the BDS statistic for 500 observations or more. They also recommend that the embedding dimension $(m)$ should be 5 or lower for a sample of the size used here and that $\varepsilon$ should be between 0.5 and 2 times the standard deviation of the data. The approximation appears not to be affected by skewness, by heavy tails or by moment conditionality failure (de Lima (1997)), but rather by bimodality or thin tails. The results of the BDS tests are shown in Table 2. The null of iid is rejected for all three returns series at the $1 \%$ level for all combinations of the user-adjustable parameters. This is consistent with similar findings in the futures \& spot currency markets (Hsieh, $1989 \&$ 1993). Rejections are strongest for the Short Sterling contract and weakest for the Long Gilt contract, but for all three contracts there is very strong evidence against the iid null hypothesis ${ }^{7}$.

In order to investigate the cause of the rejection of the null of iid, we estimate the autocorrelation coefficients and the Ljung-Box Q-Statistics of both the log price changes and the absolute values of the log price changes (Hsieh, 1993). These results are shown in Table

\footnotetext{
${ }^{7}$ The results of other tests for non-linearity were all supportive of the BDS test results shown in Table 2 and are therefore not reported here These test results are however, available on request from the authors.
} 
3. The autocorrelation coefficients and the Ljung-Box Q statistic of the absolute values of log price changes are much larger than the autocorrelation coefficients of log price changes. This suggests that the rejection of the null of iid in Table 3 is due to non-linear dynamics in the raw returns data rather than linear dynamics. The Ljung-Box $\mathrm{Q}(10)$ statistic given in the last row shows no significant evidence of autocorrelation in any of the returns series, while there is highly significant evidence of serial correlation in the absolute values of the returns.

Following the rejection of the null hypothesis of iid for each series, which is not due to linear dependence, it is likely that there is non-linear dependence in the series. However, in order to select an appropriate parametric model to characterise the series we need to know whether the non-linearity is "in-mean" or "in-variance". Hsieh $(1989,1991)$ has proposed a method for testing for non-linearity-in-mean directly. The test has the null hypothesis that the conditional mean function is zero, and is based upon the following conditional mean equation:

$$
\mu_{t}=E\left(x_{t} \mid x_{t-1}, x_{t-2}, \ldots\right)=f\left(x_{t-1}, x_{t-2}, \ldots\right)
$$

which means that,

$$
E\left(x_{t}-f\left(x_{t-1}, x_{t-2}, \ldots\right) \mid x_{t-1}, x_{t-2}, \ldots\right)=0
$$

If the conditional mean is zero, then its bicorrelation coefficients, denoted $\rho(i, j)$, $E\left[x_{t} x_{t-i} x_{t-j}\right] /\left[V\left(x_{t}\right)\right]^{3 / 2}$, are zero for $i, j \geq 1$, following the Law of Iterated Expectations. Hence, under the null hypothesis, the third order moment, $E\left[x_{t} x_{t-i} x_{t-j}\right] /\left[V\left(x_{t}\right)\right]^{3 / 2}=0$ for $i, j$ $>0$. Hsieh (1989) tests $\rho(i, j)=0$ individually using a test statistic which has a normal distribution while Hsieh $(1991,1993)$ test the composite null hypothesis that $\rho(i, j)=0$ for $0<$ $i \leq j \leq m$, for a given $m$, using a $\chi^{2}$ statistic. The results presented in Table 4 indicate little evidence for the presence of nonlinearity "in-mean" since none of the bicorrelation coefficients of the fifteen are significant, even at the $10 \%$ level for the three series. Moreover, 
in no case can the joint null hypothesis that all the bicorrelation coefficients are zero be rejected. Therefore, we can conclude that the earlier rejection of the iid null is due to the presence of non-linear dependence "in-variance".

\section{ARCH modelling and volatility persistence}

The non-linearity tests employed in the previous section have highlighted the necessity for careful modelling of the conditional variance of the futures returns since these models will form the basis of the MCRR calculations below. Rather than choosing a model a priori, we fitted a number of models to the returns series for all three contracts in an attempt to see which model was "most appropriate". The models were: $\operatorname{ARCH}(1), \operatorname{GARCH}(1,1)$, GARCH(1,1)-t, EGARCH(1,1), GJR(1,1) and an AR Volatility model ${ }^{8}$. However, one of the main criticisms of ARCH-type models is that in practice the estimated persistence is too high to reproduce observed volatility behaviour. Hamilton and Susmel (1994) addressed this problem by adopting a Markov Switching ARCH model which allowed the observed conditional variances to be drawn from more than one regime. On the other hand, Lamoureux and Lastrapes $(1990,1994)$ used the total volume of stock traded within a day, exogenously and endogenously respectively, as a way of reducing volatility persistence.

A proxy for Overnight Volatility $\left(O N V_{t}\right)$ is used in this paper to help explain the level of volatility persistence:

$$
O N V_{t}=\left|\log \frac{\text { open }_{t}}{\text { close }_{t-1}}\right|
$$

\footnotetext{
${ }^{8}$ The autoregressive volatility model is given by $x_{t}=\sigma_{p, t} u_{t}$ and $\log \sigma_{p, t}=\alpha+\sum \beta_{i} \log \sigma_{p, t-i}+v_{t}$, where $v_{t}$ is $i i d$, and $\sigma_{p, t}$ is a high/low estimator of volatility (see Hsieh, 1993, p53 for further details).
} 
where open $_{\mathrm{t}}$ is the opening price of the contract on day $t$ and close $_{\mathrm{t}-1}$ is the closing price of the contract on day $t-1$. According to Gallo and Pacini (1997), this variable may capture accumulated overnight information which may be a useful proxy for capturing the persistence in the conditional heteroscedasticity of security returns.

A number of predictive models of asset return volatility have been suggested (see, for example, Brailsford and Faff, 1996, Dimson and Marsh, 1990, or Brooks, 1998, and the references therein). The criterion which we use to choose the "best" model from the list of conditional volatility models above is the degree to which the model captures all non-linear dependence in returns. This can be tested by reapplying the BDS test to the standardised residuals $\left(\hat{\varepsilon}_{t} / \hat{h}_{t-1}^{1 / 2}\right)$ of each of the estimated ARCH models. An appropriate model is defined here as being a model whose standardised residuals are iid, since this indicates that there is no further structure left in the data. Unfortunately, as mentioned above, the BDS test is biased in favour of the null hypothesis of iid when applied to standardised residuals of ARCH-type models. New critical values need to be calculated for the standardised residuals of these models. We calculated critical values using the following steps: firstly, we generated artificial data based upon an ARCH-type model (given our coefficient estimates), we then estimated the appropriate ARCH-type model on this data, and saved the residuals from this fit, and then finally ran the BDS test on the residuals. This simulation was repeated 5,000 times. A model was then accepted as being a reasonable description of the data if the estimated value of the BDS test statistic on the standardised residuals was lower than the corresponding simulated critical value. The "best" model, given our criterion, for all three contracts proved to be the $\operatorname{GARCH}(1,1)$ model. Other models like the GARCH(1,1)-t and the autoregressive volatility model were appropriate for only one of the three contracts while the $\operatorname{EGARCH}(1,1)$ model used by Hsieh (1993) was appropriate for none of the contracts. We will therefore present 
those results which relate only to the $\operatorname{GARCH}(1,1)$ model $^{9}$. The simple GARCH $(1,1)$ model which we use to calculate the MCRRs is shown in expression (5):-

$$
\begin{aligned}
& x_{t}=\mu+\omega_{t} \\
& h_{t}=\gamma+\alpha \omega_{t-1}^{2}+\beta h_{t-1}
\end{aligned}
$$

where, $x_{t}=\log \left(P_{t} / P_{t-1}\right), \omega_{t}=h_{t}^{1 / 2} \varepsilon_{t}, \varepsilon_{t} \sim \mathrm{N}(0,1)$. The results from estimating this model for all three contracts are shown in rows 1 to 3 of Table 5. In rows 4 to 6 of Table 5, we present the basic $\operatorname{GARCH}(1,1)$ model where the conditional variance has been augmented with the inclusion of the $O N V_{t-1}$ variable. This additional variable has a large impact upon the implied volatility persistence of the returns on these contracts. The sum of the $\alpha$ and $\beta$ coefficients for the FTSE-100, Long Gilt and Short Sterling Contracts was 0.980, 0.976 and 0.924 respectively without the $O N V_{t-1}$ variable, indicating that the effect of shocks to the conditional mean would remain in the system for a long time. However, after the inclusion of $O N V_{\mathrm{t}-1}$ in the conditional variance equation in expression (5) the sum of $\alpha$ and $\beta$ coefficients are now $0.377,0.509$ and 0.404 respectively. This result will have a large impact upon the MCRR calculations which we present in Section 5 below, since a higher degree of persistence will imply that periods of high volatility are imputed by the model to last longer and therefore that higher amounts of capital should be held against positions in these securities.

\section{A methodology for estimating MCRRs}

Capital risk requirements are estimated for 1 day, 1 week, 1 month and 3 month investment horizons by simulating the conditional densities of price changes, using Efron's (1982) bootstrapping methodology based upon the $\operatorname{GARCH}(1,1)$ model presented in equation (5) and the $\operatorname{GARCH}(1,1)$ model which includes the $O N V_{t-1}$ variable (henceforth denoted

\footnotetext{
${ }^{9}$ We have calculated MCRRs using these other GARCH models, but in the interests of brevity do not report these results here. An interesting issue which we intend to pursue in future research is the extent to which the
} 
GARCH(1,1,ONV). Since the standardised residuals $\left(\hat{\varepsilon}_{t} / \hat{h}_{t-1}^{1 / 2}\right)$ from these models are iid (according to the BDS test) the $\omega_{t}$ are drawn randomly, with replacement, from the standardised residuals and a path of future $x_{t}$ 's can be generated, using the estimates of $\alpha, \beta, \gamma$ and $\mu$ from the sample and multi-step ahead forecasts of $h_{t}$. In the case of the overnight volatility variable, the long term mean is used as forecasts of its future value, as the variable (for all three contracts) is stationary and mean-reverting.

A securities firm wishing to calculate the $\mathrm{VaR}$ of a single securities position ${ }^{10}$ would have to simulate the price of the contract when it initially opened the position. To calculate the appropriate capital risk requirement, it would then have to estimate the maximum loss that the position might experience over the proposed holding period ${ }^{11}$. For example, by tracking the daily value of a long futures position and recording its lowest value over the sample period, the firm can report its maximum loss per contract for this particular simulated path of futures prices. Repeating this procedure for 20,000 simulated paths generates an empirical distribution of the maximum loss. This maximum loss $(Q)$ is given by:

$$
Q=\left(x_{0}-x_{1}\right) \times \text { Contracts }
$$

where $x_{0}$ is the price at which the contract is initially bought or sold; and $x_{1}$ is the lowest simulated price (for a long position) or the highest simulated price (for a short position) over the holding period. Assuming (without loss of generality) that the number of contracts held is 1, we can write the following:

choice of GARCH model impacts upon the MCRR.

${ }^{10}$ See Dimson and Marsh (1997) for a discussion of a number of potential issues which a financial institution may face when calculating appropriate levels of capital for multiple positions during periods of stress.

${ }^{11}$ The current BIS rules state that the MCRR should be the higher of the: (i) average MCRR over the previous 60 days or (ii) the previous trading days' MCRR. At the time of writing, it is not clear how CAD II will require the exact calculation to be made. 


$$
\frac{Q}{x_{0}}=\left(1-\frac{x_{1}}{x_{0}}\right)
$$

In this case, since $x_{0}$ is a constant, the distribution of $Q$ will depend on the distribution of $x_{1}$. Hsieh (1993) assumed that prices are lognormally distributed, i.e. that the log of the ratios of the prices, $\operatorname{Ln}\left(\frac{x_{1}}{x_{0}}\right)$, are normally distributed. However, in this paper, we do not impose this restriction, but instead, following JP Morgan's Risk-Metrics methodology, $\operatorname{Ln}\left(\frac{x_{1}}{x_{0}}\right)$ is transformed into a standard normal distribution by matching the moments of $\operatorname{Ln}\left(\frac{x_{1}}{x_{0}}\right)$,s distribution to one of a set of possible distributions known as the Johnson (1949) distribution. Matching moments to the family of Johnson distributions (Normal, Lognormal, Bounded and Unbounded) requires a specification of the transformation from the $\operatorname{Ln}\left(\frac{x_{1}}{x_{0}}\right)$ distribution to a distribution that has a standard normal distribution. In this case, matching moments means finding a distribution, whose first four moments are known, i.e. one that has the same mean, standard deviation, skewness and kurtosis as the $\operatorname{Ln}\left(\frac{x_{1}}{x_{0}}\right)$ distribution.

For all three contracts, the $\operatorname{Ln}\left(\frac{x_{1}}{x_{0}}\right)$ distributions were found to match the Unbounded distribution. Therefore, the estimated $5^{\text {th }}$ quantile of the $\operatorname{Ln}\left(\frac{x_{1}}{x_{0}}\right)$,s distribution is based on the following transformation:

$$
\operatorname{Ln}\left(\frac{x_{1}}{x_{0}}\right)_{1, t}=\sinh \left(\frac{( \pm 1.645-a)}{b}\right) \times d+c
$$


$a, b, c$ and $d$ are parameters whose values are determined by the $\operatorname{Ln}\left(\frac{x_{1}}{x_{0}}\right)$,s first 4 moments.

From expression 7, it can be seen that the distribution of $\frac{Q}{x_{0}}$ will depend on the distribution of $\frac{x_{1}}{x_{0}}$. Hence, the first step is to find the $5^{\text {th }}$ Quantile of $\operatorname{Ln}\left(\frac{x_{1}}{x_{0}}\right)$ :

$$
\frac{\operatorname{Ln}\left(\frac{x_{1}}{x_{0}}\right)-m}{S d}= \pm \alpha
$$

where $\alpha$ is the $5^{\text {th }}$ Quantile from the Johnson Distribution, $m$ is the Mean of $\operatorname{Ln}\left(\frac{x_{1}}{x_{0}}\right)$ and $S d$ is the Standard Deviation of $\operatorname{Ln}\left(\frac{x_{1}}{x_{0}}\right)$. Cross-multiplying and taking the exponential,

$$
\frac{x_{1}}{x_{0}}=\text { Exponential }[( \pm \alpha \times S d)+m]
$$

therefore

$$
\therefore \frac{Q}{x_{0}}=1-\text { Exponential }[( \pm \alpha \times S d)+m]
$$

We also use the unconditional density to calculate MCRRs so that we can make a direct comparison between the $\mathrm{ARCH}$ approach and this much simpler approach which ignores the non-linear dependence in the conditional volatility of the returns series. To use the unconditional density, the $x_{t}$ 's are drawn randomly, with replacement, from the in-sample returns.

Confidence Intervals for the MCRRs are estimated using the jackknife-after-bootstrap methodology of Efron \& Tibshirani (1993). These Confidence Intervals are estimated to give 
an idea of the likely sampling variation in the MCRR point estimates and help determine whether the differences in the MCRRs for the conditional and unconditional models are significantly different.

Assuming that, $\operatorname{Ln}\left(\frac{x_{1}}{x_{0}}\right)_{(5 \%)} \sim \mathrm{N}\left(m^{*}, S d^{*}\right)$ then, the confidence interval for the $\operatorname{Ln}\left(\frac{x_{1}}{x_{0}}\right)_{(5 \%)}$ is

$$
\left\{\operatorname{Ln}\left(\frac{x_{1}}{x_{0}}\right)_{(5 \%)} \pm 1.960 * \operatorname{SE}\left[\operatorname{Ln}\left(\frac{x_{1}}{x_{0}}\right)_{(5 \%)}\right]\right\}
$$

Therefore, the confidence interval of $\left(\frac{x_{1}}{x_{0}}\right)_{(5 \%)}$ is $\operatorname{Exp}\left\{\operatorname{Ln}\left(\frac{x_{1}}{x_{0}}\right)_{(5 \%)} \pm 1.960 * \operatorname{SE}\left[\operatorname{Ln}\left(\frac{x_{1}}{x_{0}}\right)_{(5 \%)}\right]\right\}$ and the confidence interval of $\left(\frac{Q}{x_{0}}\right)_{(5 \%)}$ is given by

$$
1-\operatorname{Exp}\left\{\operatorname{Ln}\left(\frac{x_{1}}{x_{0}}\right)_{(5 \%)} \pm 1.960 * \operatorname{SE}\left[\operatorname{Ln}\left(\frac{x_{1}}{x_{0}}\right)_{(5 \%)}\right]\right\}
$$

The jackknife-after-bootstrap provides a method of estimating the variance of the $5^{\text {th }}$ quantile of $\ln \left(x_{1} / x_{0}\right)$ using only information in the 20,000 bootstrap samples.

To verify the accuracy of this methodology, we compared the actual daily profits and losses of the three futures contracts with their daily MCRR forecasts in a hold-out sample. In this case, instead of expression (6) we will work with the following:

$$
Q=\left(x_{t}-x_{t+1}\right) \times \text { Contracts }
$$

where $x_{t}$ is the price of the contract at time $t$ and $x_{t+1}$ is the simulated price at time $t+1$. This will give us a time series of daily MCRR forecasts. Our measure of model performance is a count of the number of times the MCRR "underpredicts" future losses. It has been assumed 
that there is a 5\% chance that the observed loss exceeds the MCRR forecasts, hence if the observed loss exceeds the MCRR more than $5 \%$ of the time, we can reject the underlying model.

\section{The MCRRs}

The MCRRs for the three contracts based upon the unconditional density and the GARCH(1,1) and GARCH(1,1,ONV) models are presented in Table 6. Close inspection of Table 6 reveals that the MCRRs are always higher for short compared with long futures positions, particularly as the investment horizon is increased. This is because the distribution of log-price changes is not symmetric: there is a larger probability of a price rise in all three futures contracts than a price fall over the sample period (i.e., the mean returns in Table 1 are all positive), indicating that there is a greater probability that a loss will be sustained on a short relative to a long position. For example, the MCRR for a long Short Sterling position, calculated using the $\operatorname{GARCH}(1,1)$ model and held for three months is $2.699 \%$, but is $5.874 \%$ for a short position. The MCRRs estimated here using UK futures contracts are typically around twice those comparable figures from Hsieh (1993, table 9, p60). This difference could be attributable to the considerably higher proportion of extreme events in our sample, as evidenced by the higher degree of excess kurtosis.

The MCRRs based upon the GARCH $(1,1)$ model are always higher than for both of the alternative methods of calculation ${ }^{12}$. This result highlights the additional volatility persistence implied in the GARCH(1,1) model. A higher degree of persistence implies that a large innovation in contract returns (of either sign) causes volatility to remain high for a relatively

\footnotetext{
${ }^{12}$ In fact, excess volatility persistence will always lead to high calculated MCRRs for any model from the GARCH family.
} 
long period, and therefore the amount of capital required to cover this protracted period of higher implied volatility is also higher. The effect of this excess persistence is considerable with MCRRs increasing by a factor of three or four in most cases. For example, the MCRR GARCH(1,1,ONV) estimate for a long contract position in the Long Gilt is $9.406 \%$ for a three month investment horizon, whereas the comparable figure for the $\operatorname{GARCH}(1,1)$ model is 12.619\%. In addition, the unconditional MCRRs are always greater than those based upon the GARCH $(1,1, \mathrm{ONV})$ model. Capital requirements are highest for the contract which is most volatile, i.e. the FTSE-100 stock index futures contract, while the Short Sterling contract is least volatile of the three and therefore requires less of a capital charge. We can also see that the MCRRs are actually lower when we use the unconditional density compared with those generated using the GARCH(1,1) model in the cases of both the FTSE-100 and Long Gilt contracts. However, the conditional and unconditional MCRR estimates for a long position in the Short Sterling contract are much closer as the investment horizon increases.

Approximate $95 \%$ confidence intervals for the MCRRs calculated from the unconditional density and from the two GARCH models are presented in Table 7. The most important feature of these results is the "tightness" of the intervals around the MCRR point estimates. For example, the $95 \%$ confidence interval around the MCRR point estimates of $9.406 \%$ for a long contract position of three months in the Long Gilt using $\operatorname{GARCH}(1,1, \mathrm{ONV})$ is $9.124 \%$ to $10.393 \%$. In addition, in the cases of all three contracts the confidence intervals for the conditional GARCH and unconditional density models never overlap. This indicates that there is a highly statistically significant difference between the MCRRs generated using the conditional and unconditional densities. The lower MCRR from the former model then may be worth the extra effort and could lead to a significant decrease in the costs of maintaining positions in these securities. However, the confidence intervals estimated are considerably 
wider than those of Hsieh (1993, table 10, p61). Again, this result can be rationalised by reference to the higher proportion of large positive and large negative returns in our series.

For a fuller evaluation of the results perform an out-of-sample test of the MCRRs based upon the two GARCH models. This additional quality assurance exercise is not usually undertaken in this literature. We therefore calculated MCRRs for a 1 day investment horizon for each contract and for both short and long positions on day $t$ and then checked to see whether this MCRR had been exceeded by price movements in day $t+1$. We rolled this process forward, recalculating the MCRRs etc, for 500 days, i.e. using the sample period $17^{\text {th }}$ September 1996 to 12 August 1998. Panel A of table 8 shows the number of volations of the MCRR estimates generated by sampling from the unconditional distribution of returns. For both the FTSE-100 and Long Gilt futures, the number of violations marginally exceeds the 5\% nominal value, indicating that the MCRRs generated in this fashion were insufficient to cover losses on $6 \%$ of the days in the hold-out sample. The GARCH(1,1) results without ONV presented in Panel B of Table 8 show that the realised percentages of MCRR violations (for both long and short positions) are far lower than the nominal 5\% coverage, indicating that the volatility persistence in the $\operatorname{GARCH}(1,1)$ models has led to too high a capital charge being imposed compared with that necessary to give a true 5\% coverage. However, the results for the GARCH(1,1,ONV) model in Panel C of Table 8 show that for the FTSE-100 Index and the Long Gilt contracts, the calculated daily MCRR was exceeded on exactly $5 \%$ of occasions during our 500 day hold-out sample for both long and the short positions. Thus we believe this result to be a strong validation of our approach. The number of exceedences in the out of sample period for the Short sterling contract is $3 \%$ for both long and short positions, indicating that the estimated MCRRs are slightly excessive, although they are still closer to the nominal 5\% level than their counterparts calculated using the $\operatorname{GARCH}(1,1)$ model. 


\section{Conclusions}

Under CAD II, European banks and investment firms will shortly be able to calculate appropriate levels of capital for their trading books using IRMMs. It is expected that these models will be in widespread usage, particularly in London, soon after the necessary legislation has been passed. Given this development in the international regulatory environment, this paper investigated certain aspects of this technology by calculating MCRRs for three of the most popular derivatives contracts currently trading on LIFFE. Our results indicate that MCRRs based upon GARCH-type models which are designed to take explicit account of the persistence normally implied in such models, might be as much as two times lower than those MCRRs calculated from ARCH models which do not take account of this phenomenon. Moreover, in a hold-out sample of two trading years, the GARCH model modified to include ONV gives proportions of exceedences which are much closer to the nominal $95 \%$ coverage rate than a pure $\operatorname{GARCH}(1,1)$ or an unconditional model.

While we are not suggesting that our method is the best approach to the problem, since there were many other alternative and valid adjustments which we could have made to the model, we do believe that our results should serve as a word of warning to those banks and securities firms which are currently using (under BIS rules), or are planning to use (under CAD II) technology of this kind to calculate appropriate MCRRs against such positions. Practitioners who use models from the GARCH family, but do not take into account the excess volatility persistence implied by the estimated models, are in danger of biasing their estimated capital requirements upwards, thus potentially wasting valuable resources. 


\section{References}

Brailsford, JJ. And R.W. Faff, 1996, An Evaluation of Volatility Forecasting Techniques, Journal of Banking and Finance, 20, 419-438.

Brock, W., W.Dechert and J.Scheinkman, B. LeBaron, 1996, A Test for Independence based on the Correlation Dimension, Econometric Reviews 15, pp 197-235.

Brock, W., D. Hsieh, and B. LeBaron, 1991, Nonlinear Dynamics, Chaos and Instability: Statistical Theory and Economic Evidence. Cambridge, MA: MIT Press.

Brooks, C., 1998, Forecasting Stock Return Volatility: Does Volume Help, Journal of Forecasting 17, 59-80

Clifford Chance, 1998, CADII moves forward, Newsletter: European Financial Markets, London.

Cantor, R. and F. Packer, 1997, Differences of Opinion and Selection Bias the Credit Rating Industry, 21,1395-1417.

De Lima, P.J.F., 1997, On the Robustness of Nonlinearity Tests to Moment Condition Failure, Journal of Econometrics 76, pp 251-280.

Dimson, E. and P.Marsh, 1997, Stress Tests of Capital Requirements, Journal of Banking and Finance 21, 1515-1546.

Dimson, E., and P.Marsh, 1995, Capital Requirements for Securities Firms, Journal of Finance, Vol L, No. 3, pp 821-851.

Dimson, E., and P.Marsh, 1990, Volatility Forecasting without Data Snooping, Journal of Banking and Finance, 14, 399-425

Efron, B., 1982, The Jackknife, the Bootstrap, and Other Resampling Plans, Philadelphia, PA: Society for Industrial and Applied Mathematics.

Efron, B., and R.Tibshirani, 1993, An Introduction to the Bootstrap, Chapman Hall.

Engle, R., 1982, Autoregressive Conditional Heteroscedasticity with Estimates of the Variance of U.K. Inflations, Econometrica 50, pp 987-1007.

Gallo, G.M., and B.Pacini., 1997, The Effects of Trading Activity on Market Volatility, Forecasting Financial Markets: Advances for Exchange Rates, Interest Rates and Asset Management, Fourth International Conference sponsored by the Banque Nationale de Paris and Imperial College, Applied Econometrics Association, London, May 1997.

Hamilton, J.D., and R.Susmel, 1994, Autoregressive Conditional Heteroscedasticity and Changes in Regime, Journal of Econometrics 64, pp 307-333.

Hsieh, D.A., 1989, Testing for Nonlinearity in daily Foreign Exchange Rate Changes, Journal of Business 62, pp 339-368. 
Hsieh, D.A., 1991, Chaos and Nonlinear Dynamics: Application to Financial Markets, Journal of Finance 46, pp 1839-1877.

Hsieh, D.A., 1993, Implications of Nonlinear Dynamics for Financial Risk Management, Journal of Financial and Quantitative Analysis 28, pp 41-64.

Johnson, N.L., 1949, Systems of Frequency Curves Generated by Methods of Translations, Biometrika, pp149-175.

Lamoureux, C., and W.D.Lastrapes, 1990, Heteroscedasticity in Stock Return Data: Volume versus GARCH Effects, Journal of Finance 45, pp 221-229. 
TABLE 1

Summary Statistics of Derivative Returns

\begin{tabular}{cccc}
\hline Futures Contracts & FTSE-100 Index & Long Gilt & Short Sterling \\
\hline Mean & 1.73 & 0.31 & 0.07 \\
Variance & 0.22 & 0.07 & 0.00 \\
Skewness & $-1.58^{*}$ & $0.105^{*}$ & $2.71^{*}$ \\
Kurtosis & $24.67^{*}$ & $3.27^{*}$ & $53.02^{*}$ \\
Normality Test Statistic $\dagger$ & $74273.66^{*}$ & $1371.00^{*}$ & $348140.30^{*}$ \\
\hline
\end{tabular}

Notes: Mean and variance are given in terms of basis points. * represents significance at the $5 \%$ level (2 tailed-test); $\dagger$ Bera and Jarque test

TABLE 2

BDS Test Statistic for Derivative Returns

\begin{tabular}{llcccc}
\hline $\boldsymbol{\varepsilon} / \boldsymbol{\sigma}$ & Contracts & \multicolumn{4}{c}{ Embedding Dimensions } \\
\hline & & $\mathbf{2}$ & $\mathbf{3}$ & $\mathbf{4}$ & $\mathbf{5}$ \\
\multirow{2}{*}{$\mathbf{0 . 5 0}$} & FTSE-100 Index & 5.18 & 7.44 & 8.92 & 9.84 \\
& Long Gilt & 4.88 & 7.08 & 9.44 & 11.17 \\
& Short Sterling & 13.32 & 18.06 & 22.42 & 27.80 \\
& & & & & \\
\multirow{2}{*1.00}{} & FTSE-100 Index & 6.32 & 8.59 & 9.84 & 10.72 \\
& Long Gilt & 5.40 & 7.86 & 10.11 & 12.02 \\
& Short Sterling & 12.70 & 15.49 & 17.30 & 19.11 \\
& & & & & \\
$\mathbf{1 . 5 0}$ & FTSE-100 Index & 8.24 & 10.38 & 11.32 & 11.92 \\
& Long Gilt & 6.06 & 8.29 & 10.01 & 11.58 \\
& Short Sterling & 10.53 & 12.62 & 13.38 & 14.18 \\
\hline
\end{tabular}


TABLE 3

Autocorrelations of Derivative Returns

\begin{tabular}{ccccccc}
\hline & \multicolumn{2}{c}{ FTSE-100 Index } & \multicolumn{2}{c}{ Long Gilt } & \multicolumn{2}{c}{ Short Sterling } \\
\hline $\begin{array}{c}\text { Lag } \\
\text { Length }\end{array}$ & Returns & $\begin{array}{c}\text { Absolute } \\
\text { Return }\end{array}$ & Returns & $\begin{array}{c}\text { Absolute } \\
\text { Return }\end{array}$ & Returns & $\begin{array}{c}\text { Absolute } \\
\text { Return }\end{array}$ \\
$\mathbf{1}$ & 0.01 & 0.26 & -0.02 & 0.11 & 0.01 & 0.18 \\
$\mathbf{2}$ & -0.02 & 0.26 & -0.02 & 0.12 & -0.02 & 0.18 \\
$\mathbf{3}$ & 0.02 & 0.20 & -0.01 & 0.14 & 0.01 & 0.13 \\
$\mathbf{4}$ & 0.04 & 0.14 & 0.00 & 0.15 & -0.02 & 0.13 \\
$\mathbf{5}$ & 0.00 & 0.16 & 0.03 & 0.11 & 0.01 & 0.12 \\
$\mathbf{6}$ & -0.02 & 0.17 & -0.01 & 0.13 & 0.02 & 0.10 \\
$\mathbf{7}$ & 0.00 & 0.15 & -0.03 & 0.12 & 0.00 & 0.08 \\
$\mathbf{8}$ & 0.03 & 0.14 & 0.04 & 0.12 & 0.00 & 0.12 \\
$\mathbf{9}$ & 0.01 & 0.18 & 0.03 & 0.09 & -0.02 & 0.11 \\
$\mathbf{1 0}$ & 0.02 & 0.14 & 0.01 & 0.12 & 0.02 & 0.15 \\
$\mathbf{Q}(\mathbf{1 0})$ & 11.61 & $1022.65^{*}$ & 17.26 & $445.95^{*}$ & 18.00 & $525.17 *$ \\
\hline
\end{tabular}

Note: * represents significance at $1 \%$ level.

TABLE 4

Bicorrelation Coefficients of Derivative Returns

\begin{tabular}{llccc}
\hline $\mathbf{i}$ & $\mathbf{j}$ & FTSE-100 Index & Long Gilt & Short Sterling \\
\hline $\mathbf{1}$ & $\mathbf{1}$ & -0.57 & 0.09 & 0.25 \\
$\mathbf{1}$ & $\mathbf{2}$ & 0.47 & -0.01 & 0.01 \\
$\mathbf{2}$ & $\mathbf{2}$ & 0.29 & -0.01 & 0.35 \\
$\mathbf{1}$ & $\mathbf{3}$ & 0.29 & 0.04 & -0.04 \\
$\mathbf{2}$ & $\mathbf{3}$ & -0.16 & 0.03 & -0.03 \\
$\mathbf{3}$ & $\mathbf{3}$ & -0.65 & -0.02 & 0.18 \\
$\mathbf{1}$ & $\mathbf{4}$ & -0.18 & 0.02 & 0.13 \\
$\mathbf{2}$ & $\mathbf{4}$ & 0.10 & -0.01 & 0.09 \\
$\mathbf{3}$ & $\mathbf{4}$ & -0.15 & 0.03 & -0.03 \\
$\mathbf{4}$ & $\mathbf{4}$ & -0.34 & 0.01 & 0.02 \\
$\mathbf{1}$ & $\mathbf{5}$ & 0.02 & -0.01 & -0.04 \\
$\mathbf{2}$ & $\mathbf{5}$ & -0.12 & 0.00 & 0.05 \\
$\mathbf{3}$ & $\mathbf{5}$ & 0.20 & 0.04 & 0.06 \\
$\mathbf{4}$ & $\mathbf{5}$ & -0.15 & -0.07 & 0.04 \\
$\mathbf{5}$ & $\mathbf{5}$ & -0.28 & 0.01 & -0.11 \\
& $\boldsymbol{\chi}^{\mathbf{2}(\mathbf{1 5})}$ & 17.65 & 15.87 & 19.46 \\
\hline
\end{tabular}


TABLE 5

Coefficient Estimates of GARCH(1,1) and GARCH(1,1,ONV) Models

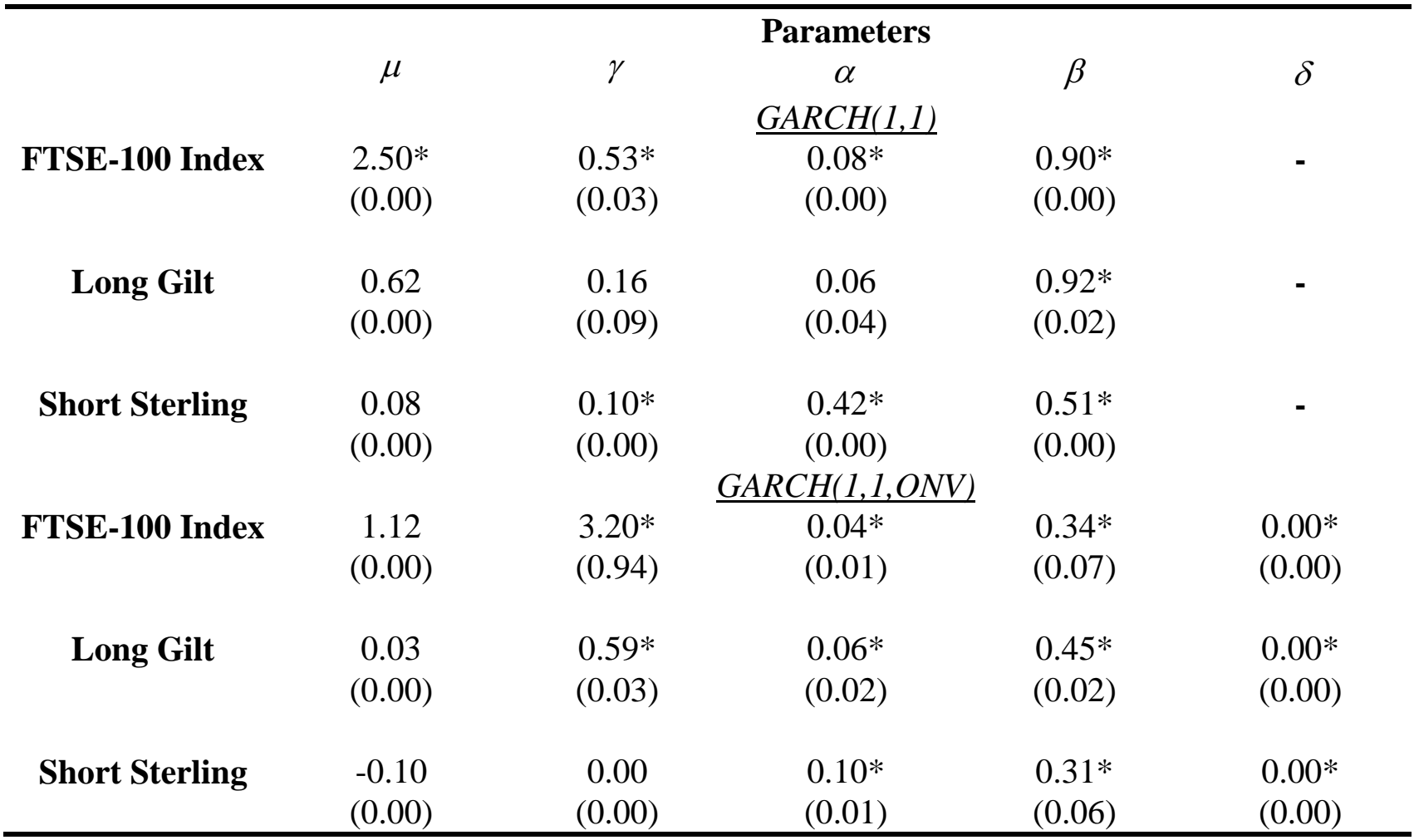

Notes: $\mu$ is given in terms of basis points; All entries in the $\gamma$ column (both coefficients and their standard errors) have been multiplied by 100,000 ; standard errors are in parentheses; * indicates significance at the $5 \%$ level. 
TABLE 6

Capital Requirement for $95 \%$ Coverage Probability as a Percentage of the Initial Value for Unconditional Density and based on GARCH(1,1) model, both with and without the Overnight Volatility Variable.

\begin{tabular}{|c|c|c|c|c|c|c|}
\hline \multirow[t]{3}{*}{ Horizon } & \multicolumn{3}{|c|}{ Long Positions } & \multicolumn{3}{|c|}{ Short Positions } \\
\hline & Uncond. & $\operatorname{GARCH}(\mathbf{1 , 1})$ & GARCH(1,1,ONV) & Uncond. & $\operatorname{GARCH}(\mathbf{1 , 1})$ & GARCH(1,1,ONV) \\
\hline & \multicolumn{6}{|c|}{ FTSE-100 Index } \\
\hline 1 day & 1.67 & 4.01 & 2.44 & 2.62 & 5.09 & 3.45 \\
\hline 1 week & 4.62 & 5.99 & 5.08 & 7.62 & 9.43 & 8.19 \\
\hline 1 month & 10.91 & 14.56 & 11.61 & 14.74 & 17.87 & 15.40 \\
\hline \multirow[t]{2}{*}{3 months } & 15.39 & 19.24 & 15.67 & 22.24 & 25.75 & 22.62 \\
\hline & \multicolumn{6}{|c|}{ Long Gilt } \\
\hline 1 day & 1.34 & 3.03 & 2.32 & 2.35 & 3.38 & 2.93 \\
\hline 1 week & 3.86 & 7.02 & 4.77 & 5.91 & 7.67 & 6.50 \\
\hline 1 month & 5.24 & 8.74 & 6.16 & 9.47 & 10.62 & 10.00 \\
\hline \multirow[t]{2}{*}{3 months } & 8.83 & 12.62 & 9.41 & 12.53 & 13.92 & 13.00 \\
\hline & \multicolumn{6}{|c|}{ Short Sterling } \\
\hline 1 day & 0.29 & 1.06 & 0.58 & 0.60 & 1.46 & 1.01 \\
\hline 1 week & 0.71 & 1.51 & 1.04 & 1.27 & 2.90 & 2.03 \\
\hline 1 month & 1.58 & 2.40 & 2.13 & 2.00 & 4.52 & 3.07 \\
\hline 3 months & 2.02 & 2.70 & 2.26 & 3.26 & 5.87 & 4.10 \\
\hline
\end{tabular}



TABLE 7

Approximate 95\% Central Confidence Intervals for the MCRRs given in Table 6.

\begin{tabular}{|c|c|c|c|c|c|c|}
\hline \multirow[t]{3}{*}{ Horizon } & \multicolumn{3}{|c|}{ Long Positions } & \multicolumn{3}{|c|}{ Short Positions } \\
\hline & Uncond. & $\operatorname{GARCH}(\mathbf{1 , 1})$ & GARCH(1,1,ONV) & Uncond. & $\operatorname{GARCH}(\mathbf{1 , 1})$ & GARCH(1,1,ONV) \\
\hline & \multicolumn{6}{|c|}{ FTSE-100 Index } \\
\hline 1 day & {$[1.61,1.88]$} & {$[3.81,4.52]$} & {$[2.37,2.67]$} & {$[2.51,2.94]$} & {$[4.83,5.72]$} & {$[3.35,3.81]$} \\
\hline 1 week & {$[4.44,5.20]$} & {$[5.69,6.73]$} & {$[4.93,5.61]$} & {$[7.32,8.56]$} & {$[8.96,10.61]$} & {$[7.94,9.05]$} \\
\hline 1 month & {$[10.48,12.26]$} & {$[13.83,16.37]$} & {$[11.26,12.82]$} & {$[14.15,16.56]$} & {$[16.97,20.10]$} & {$[14.94,17.02]$} \\
\hline \multirow[t]{2}{*}{3 months } & {$[14.78,17.28]$} & {$[18.28,21.64]$} & {$[15.20,17.31]$} & {$[21.35,24.98]$} & {$[24.46,28.97]$} & {$[21.94,25.00]$} \\
\hline & \multicolumn{6}{|c|}{ Long Gilt } \\
\hline 1 day & {$[1.29,1.51]$} & {$[2.88,3.40]$} & {$[2.25,2.56]$} & {$[2.26,2.64]$} & {$[3.21,3.80]$} & {$[2.84,3.23]$} \\
\hline 1 week & {$[3.71,4.34]$} & {$[6.67,7.90]$} & {$[4.62,5.26]$} & {$[5.67,6.64]$} & {$[7.28,8.63]$} & {$[6.31,7.19]$} \\
\hline 1 month & {$[5.03,5.89]$} & {$[8.30,9.83]$} & {$[5.98,6.80]$} & {$[9.09,10.63]$} & {$[10.09,11.95]$} & {$[9.70,11.04]$} \\
\hline \multirow[t]{2}{*}{3 months } & {$[8.48,9.92]$} & {$[11.99,14.12]$} & {$[9.12,10.39]$} & {$[12.03,14.07]$} & {$[13.22,15.66]$} & {$[12.61,14.36]$} \\
\hline & \multicolumn{6}{|c|}{ Short Sterling } \\
\hline 1 day & {$[0.27,0.32]$} & {$[1.01,1.19]$} & {$[0.56,0.64]$} & {$[0.58,0.67]$} & {$[1.38,1.64]$} & {$[0.98,1.12]$} \\
\hline 1 week & {$[0.68,0.80]$} & {$[1.44,1.70]$} & {$[1.01,1.15]$} & {$[1.22,1.42]$} & {$[2.75,3.26]$} & {$[1.97,2.24]$} \\
\hline 1 month & {$[1.52,1.77]$} & {$[2.28,2.70]$} & {$[2.06,2.35]$} & {$[1.92,2.25]$} & {$[4.29,5.08]$} & {$[2.98,3.39]$} \\
\hline 3 months & {$[1.94,2.27]$} & {$[2.56,3.04]$} & {$[2.19,2.50]$} & {$[3.13,3.66]$} & {$[5.58,6.61]$} & {$[3.98,4.53]$} \\
\hline
\end{tabular}


TABLE 8

Out-of-Sample tests: Realised Percentages of MCRR Violations calculated using both the GARCH(1,1) and GARCH(1,1,ONV) models and the Unconditional Density.

\begin{tabular}{lcc}
\hline Contract & Long Position & Short Position \\
\hline & \multicolumn{2}{c}{ Panel A: Unconditional Density } \\
FTSE-100 Index & $6.2 \%$ & $5.8 \%$ \\
Long Gilt & $6.4 \%$ & $6.0 \%$ \\
Short Sterling & $4.2 \%$ & $3.4 \%$ \\
& \multicolumn{2}{c}{ Panel B: GARCH $(1,1)$} \\
FTSE-100 Index & $2.8 \%$ & $2.2 \%$ \\
Long Gilt & $3.0 \%$ & $2.2 \%$ \\
Short Sterling & $1.2 \%$ & $0.6 \%$ \\
& \multicolumn{2}{c}{ Panel C: GARCH(1,1,ONV) } \\
FTSE-100 Index & $5.2 \%$ & $4.8 \%$ \\
Long Gilt & $5.0 \%$ & $4.2 \%$ \\
Short Sterling & $3.4 \%$ & $3.4 \%$ \\
\hline
\end{tabular}

Note: the nominal probability of MCRR violations was set at 5\% (see text for more details). 